\section{A data-input and -analysis system using an optical scanner}

\author{
ELLEN F. ROSEN \\ College of William and Mary, Williamsburg, Virginia
}

and

LINDA C. PETTY

Hampton Institute, Hampton University, Hampton, Virginia

Two problems occur in the collection of large quantities of research data: the gathering and coding of the raw data, and the analysis of the data. Computers linked with optical scoring devices simplify both tasks. The optical scanner permits subjects to code their own data. Because questions appear in a precoded format, subjects are able to answer the questions by using a No. 2 pencil to blacken the boxes corresponding to their choices. The researcher then simply feeds the answer sheets through the scanning system, which acts as an input-only terminal to the computer. With the appropriate information to the proper software, the data file is effortlessly constructed. Then the analysis proceeds rapidly through the use of software that accesses the data files directly.

Often, statistical analysis programs place restrictions on the arrangement of the data file. However, FORTRAN allows the user to input the file structure of the data set at the time of analysis.

The data-analysis system reported here uses an optical scanning device (Model 5500, Visual Products Division, $3 \mathrm{M}$ Co.) connected via an RS-232C (DZ11 asynchronous multiplexer) port to a PDP-11/34 computer running under a real-time operating system (RSX11M, Digital Equipment Corporation, Maynard, MA). The programs are written in FORTRAN IV Plus and are controlled by an indirect command file that provides some helpful information to the user and actually executes the programs. Therefore, some understanding of format statements is required of the user. A menu (see Table 1) of five programs is currently available. The use of the command file requires about $20 \mathrm{~K}$ words of workspace for the largest of the programs; without it, a smaller computer can be used. In fact, with a suitable microcomputer and a readaccessible RS-232C port, the principles should be identical. FORTRAN IV Plus makes assessing such a port very simple.

A listing of the module that reads from the scanner is presented in Table 2. The use of the CALL ASSIGN com-

Please send inquiries regarding the programs to: Linda C. Petty, Department of Psychology, Hampton Institute, Hampton University, Hampton, VA 23668. mand assigns the logical unit number to the device known to the computer as TT1: (a read-only terminal). With a microcomputer, such as the DEC Rainbow, the scanner can probably be connected to the standard RS-232C communications port. The computer then responds as though it is connected to another computer (this may require reversing lines 2 and 3 on the optical scanner RS-232C cable). After the data file is constructed, BASIC language programs can be written for data analysis. The disadvantage in using BASIC is that commas are required between each variable in the data file.

A difficulty with this system is that subjects occasionally make mistakes in marking the boxes on the data sheets. Sometimes subjects do not erase well or they blacken too many boxes.

This particular optical scanner codes numbers higher than 5 by using two marks (e.g., to produce 7 , blacken 5 and 2). Because letters are encoded with multiple marks, subject errors in coding can produce letters instead of numbers. When the file is created using the SCORER FORTRAN module, a column of data is read in as one line using the string-variable format code (A). Thus, the code must be checked to see whether there are any letters in the data file. When there are many numbers, this becomes too tedious with a system editor. Consequently, another module, CHECKER, has been created.

This package (Table 1) also includes four data-analysis programs: (1) FREQUENC, to generate frequencies and percentages; (2) CHI, to generate two-way and three-way contingency tables and to calculate chi-squares for the two tables if so desired; (3) CORRELAT, to generate Pearson correlation matrices and to calculate the $t$ value to test the hypothesis of no correlation; and (4) ANOVA, to perform a one-way independent-groups analysis of variance.

System Requirements. The modules are written in FORTRAN IV Plus. This system was written for a PDP$11 / 34$ with $128 \mathrm{~K}$ words of memory running under RSX11M. The optical scanner is connected to the computer using a DZ11 (RS-232C) interface. The computer system has one fixed and one removable RK05 disk. The scanner is a slave (input-only) terminal. The data are stored on disk as a FORTRAN data file. With minor modifications, the system will probably work on any computer that has FORTRAN. However, the command file requires the RSX operating system. Some of the programs use a free-format READ statement and therefore may require some minor modifications. The programs are interactive and prompt the entry of the data-file format statement and data-file names.

Availability. A listing of the program modules and command file are available at no cost from the second author. The programs can also be obtained on RK05 disk if a suitable disk is provided. 
Table 1

Menu

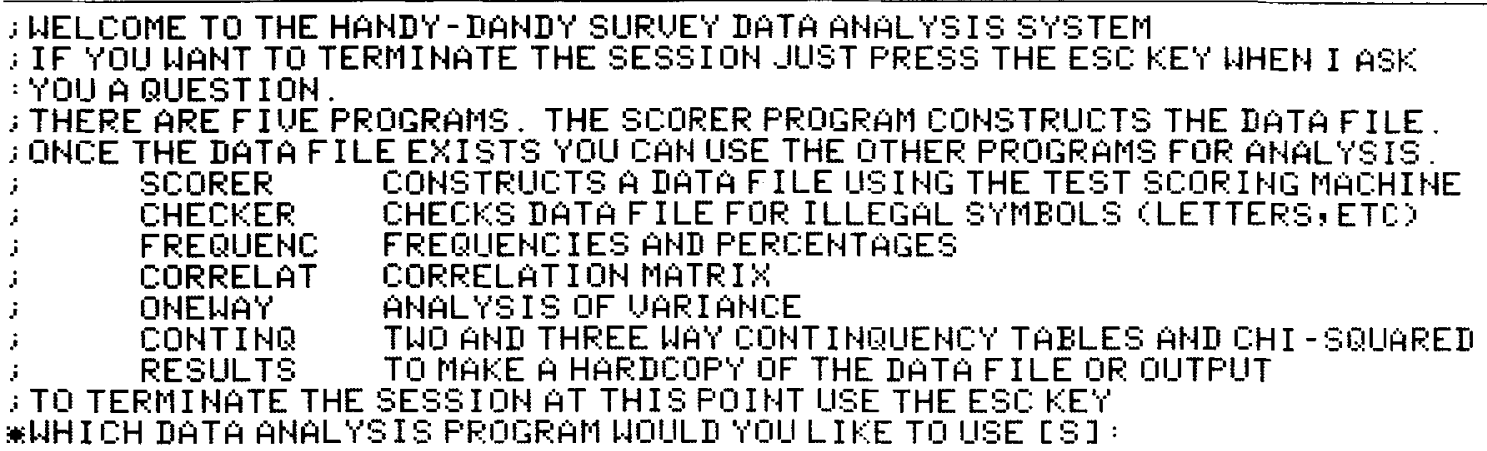

Table 2

SCORER Program Listing

LOG ICAL* 1 OUTF IL $(24)$

BYTE IATAC50)

IHTEGER HL IHES (4)

CALL ASSIINC1, 'TT $1:$ '

GALL ASSIGHC, ' T I : '

WR I TE $(2,881)$

B81 FORMATC' EHTER HAME OF DUTFUT FILE CHOMORE THAH 23 SYMBOLS)'

ACDEEPT BQZ, DUTFIL

OUTF IL 24$)=0$

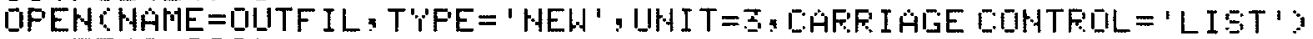

WF I TE 2,882$)$

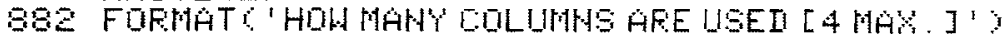

REAIC5, OHCOLS

IIO $890 \mathrm{I}=1$, HCOLS

HFI ITE, 895 I

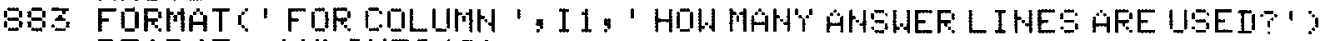

REAIIS, $)$ YHL INESCI

890 CONT IHUE

W.A ITE 2,8011$)$

BQ1 FORMAT' ' HOW MAN'Y ANSWER SHEETS ARE YOU FEAIIHI INT'?

FEADCZ: $⿻$ SHSHEET

UR I TE $(2,804)$

804 FGRMAT' ' HOW PIIT THE SHEETS IH THROULH THE SCAHHER. IHSEFT EACH', $1 \%, ' S H E E T$ COMPLETEL $Y$ EEF ORE GOINI OH TO THE HEXT DNE. ', ' THIS Z MEANS THAT IF YOUARE USING THO COLUMWS OF ANSWERS FER SHEET

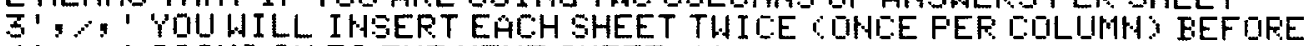
4 ', 9 ' GOIHG OH TO THE NEXT SHEET . ' ?

IDO 200 I $=1$, HSHEET

nO $200 . J . J=1, N D O L S$

REAIC 1,803 ) (IATACI,$I=1$, HLIHESCIJ)

BQS FORMATSSGA1)

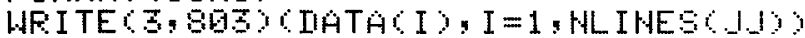

20E COHT INUE

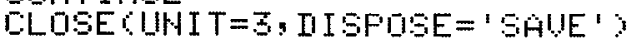

WFI ITE $(2,805)$

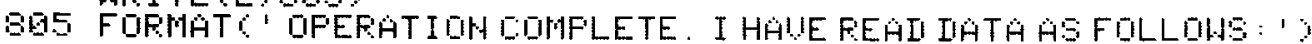

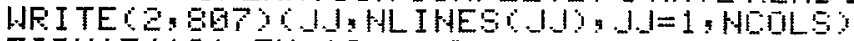

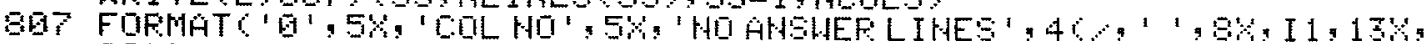
I2) $\mathrm{Y}$

SGS FURHAT ' GFOF: ' IE, ' SHEETS. THE IATA IS STOREI IH THE FILE', 3'GCALLEI: ' $24 A 1$;

HR I TEC, BUS SHSHEET, OUTF IL

STOP

EHII

(Revision accepted for publication February 12, 1985.) 